\title{
Transformasi Dakwah di Masa Pandemi Covid-19
}

\author{
Ibnu Hajar S \\ STAI DDI Kota Makassar \\ Email: dewaibnuhajar@gmail.com
}

\begin{abstract}
ABSTRAK
Saat ini dunia dilanda krisis akibat muncunya covid-19 dan berdampak pada kehidupan sosial di masyarakat. Dakwah pada dasarnya adalah suatu kebutuhan bagi umat Islam. Dakwah merupakan salah satu cara untuk menyapaikan pesan-pesan kebaikan kepada masyarakat. Terjadi transformasi dalam kegiatan dakwah sejak masa pandemi . Perubahan tersebut yang biasanya dilakukan secara klasik atau tatap muka antara dai dan mad'u sekarang bertransformasi berubah melalui platform media sosial daring yang tersedia. Jika dikaitkan dengan perubahan era informasi yang semakin kompleks, maka banyak masalah yang harus dihadapi dan perlu penyelesain melalui pesan-pesan dakwah. Oleh karena itu, sebagai dai penting untuk mengetahui dan mengoperasikan platform media daring berbasis virtual untuk menyampaikan pesa-pesan dakwah kepada masyarakat khalayak. Materi-materi yang disampaikan berkaitan dengan situasi dan kondisi yang sedang terjadi.
\end{abstract}

\section{Kata Kunci: Transformasi, Dakwah, Pandemi covid-19.}

\section{Pendahuluan}

Sejatinya dakwah adalah mengajak manusia kepada jalan kebaikan. Tujuan menyampaikan pesan-pesan kebaikan kepada masyarakat, baik kepada yang muslim maupun non-muslim adalah agar terjadi perubahan pada diri secara spritual.[1] Keberhasilan dakwah sebagai kegiatan meyampaikan pesan-pesan kebaikan ketika perilaku keseharian masyarakat berubah baik secara pribadi maupun secara kolektif.

Seiring terjadinya perubahan kehidupan masyarakat yang serba mengandalkan teknologi berbasis media online, secara otomatis kegiatan dakwah juga ikut terpengaruh.[2] Kegiatan dakwah yang biasanya dilakukan secara tatap muka bersama mad'u sekarang berubah melalui perantara media sosial atau platform media online yang lainnya yang dinilai cukup efektif untuk melakukan kegiatan dakwah.

Melihat realitas, maka terjadi transformasi dakwah dimasa pandemi sekarang ini cukup siknifkan dan dianggap cukup efektif dan efisien baik secara waktu maupun tempat.

\section{Pembahasan}

Islam adalah agama rahmatan lil alamin. Islam disebarkan melalui pesan-pesan kedamaian dengan membawa ketenangan bagi para penganutnya.[3] Islam juga selalu berusaha untuk menjaga hubungan kepada siapa pun baik yang beragama muslim maupun non-muslim.[4] Pesan-pesan kedamaian itu berupa pesan yang mengadung unsur kebaikan yang disebur sebagai pesan dakwah.

Dakwah pada dasarnya adalah usaha dalam mengajak manusia ke arah proses yang lebih baik secara kolektif maupun individu agar menjadi manusia yang terbaik.[5] Dakwah menjadi kebutuhan bagi setiap orang khususnya umat Islam.[6] Karena dakwah menjadi kebutuhan, maka para dai menggunakan berbagai cara untuk menyampaikan pesan-pesan dakwah.

Di masa pandemi sekarang ini, terjadi perubahan yang cukup signifikan dalam kehidupan masyarakat.[7] Perubahan itu adalah berubahnya kegiatan yang dilakukan secara klasik menjadi kegiatan yang serba mengandalkan teknologi baik berupa media sosial maupun media online lainnya yang berbasis virtual.

Transformasi dakwah di masa pandemi covid-19 menjadi salah satu strategi dakwah yang dilakukan orang para dai. Transformasi ini dilakukan secara struktural yang bergerak dari top down 
maupun secara kultural yang bergerak dar bottom up.[8] Oleh karena itu, dengan strategi dakwah ini dapat memudahkan masyarakat untuk medapatkan informasi yang berkaitan dengan nilai-nilai islam.

Transformasi dakwah di masa pandemi covid-19 sekarang ini. Platform-platform media sosial dan media online lainnya yang berbasis virtual yang tersedia menjadi salah satu cara alternatif untuk menyampaikan pesan-pesan keagamaan.[9] Ini dianggap sebagai salah cara yang cukuf efektif karena mudah dijangkau.

Pada masa sebelum terjadi pandemi covid-19, dakwah disampaikan tanpa melalui media dan dilakukan secara langsung dengan bertatap muka antara dai dan mad'u.[10] Sekarang ini, media menjadi paling utama untuk mendapatkan informasi-informasi yang terkait dengan keagamaan.

Selama masa pandemi covid-19, dakwah merupakan salah satu cara untuk melakukan perubahan sosial baik secara individu maupun secara kelompok.[11] Masyarakat membutuhkan bimbingan secara spritual karena sebelumnya banyak beraktivitas yang cukup menguras tenaga dan pikiran sehingga terjadi krisis spiritual. Oleh karena itu, transformasi dakwah di masa pandemi sekerang ini, yang semula hanya dilakukan secara klasik, sekarang berubah menjadi serba berbasi media online.

Di masa pandemi covid-19 juga membuat ritual-ritual keagamaan juga berpengaruh seperti kegiatan haji dan umrah.[12] Berdasarkan hasil keputusan pemerintah dengan berbagai macam pertimbangan khususnya dari segi kesehatan, maka pelaksanaan kegiatan haji maupun umrah untuk sementara ditiadakan. Oleh karena itu, maka kegiatan manasik haji dan umrah juga ditiadakan.

Pandemi covid-19 menjadikan dan memaksa manusia selalu berpikir kreatif. Dengan media sosial dan media online yang berbasis virtual dapat membuat masyarakat lebih mudah dalam medapatkan informasi.[13] tanpa harus mengeluarkan tenaga untuk mendatangi suatu majelis, akan tetapi cukup dengan mengaktifkan media online berbasis virtual, maka kajian keislaman dapat terakses dan dapat diikuti dengan mudah dan lebih efektif.

Hakekat tranformasi dakwah di masa pandemi covid-19 ini, agar membuat masyarakat khususnya umat islam agar lebih mudah dalam mendaptakan informasi terkait dengan keIslaman yang dapat memberikan kemudahan sehingga terjadi perubahan dari segi spiritual dengan berbasis nilainilai agama.

Artikel ini menunjukka bahwa transformasi dakwah pada masa pandemi ini merupakan bagian dari strategi dalam menyampaika pesan-pesan agama dengan lebih mudah. Berbanding dengan temuan Ahmad, H., \& Amin, E. yang khusus mengkaji integrasi ayat-ayat al-Quran [14] sementara Rozikan,M mengkaji terkait Konseling Islam [15]. Adapun Uswatusolihah, U. Mengkaji kesadaran dan transformasi diri dalam kajian dakwah Islam [16]. Untuk itu, artikel ini menegaskan bahwa transformasi dakwah di masa pandemi covid-19 menjadi alternatif untuk mendapatkan informasi dan pesan-pesan agama yang lebih mudah.

\section{Kesimpulan}

Dengan terjadinya covid 19, maka turut mempengaruhi pola pikir masyarakat. Transformasi dakwah dengan melalui fltafor media online dan teknologi lainnya dianggap cukup efektif dalam menyebarkan pesan-pesan agama dan menjadi suatu kebutuhan masyarakat khususnya umat islam yang sebelumnya terjadi distorsi secara spiritual. Oleh karena itu, dengan tranformasi dakwah ini menjadi salah satu cara alternatif baik menyampaikan maupun dalam mendapatkan pesan-pesan agama. 


\section{Daftar Pustaka}

[1] Hizbullah, M. (2018). Dakwah Harakah, Radikalisme, dan Tantangannya di Indonesia. Misykat Al-Anwar, 29(2).

[2] Wibawa, A. T. (2019). FENOMENA DAKWAH DI MEDIA SOSIAL YOUTUBE. Jurnal RASI, 1(1), 1-21.

[3] Siregar, M. (2015). MENYERU TANPA HINAAN (Upaya Menyemai Dakwah Humanis Pada Masyarakat Kota Langsa yang Pluralis). Jurnal Dakwah, 16(2), 203-229.

[4] Wekke, I. S. (2013). Islam di Papua Barat: tradisi dan keberagaman. ULUL ALBAB Jurnal Studi Islam, 14(2), 117-134.

[5] Farihah, I. (2016). Pengembangan Karier Pustakawan melalui Jabatan Fungsional Perpustakaan sebagai Media Dakwah. LIBRARIA: Jurnal Perpustakaan, 2(1).

[6] Hasanah, H. (2016). Arah Pengembangan Dakwah melalui Sistem Komunikasi Islam. At-Tabsyir: Jurnal Komunikasi Penyiaran Islam, 4(1), 131-56.

[7] Na'afi, S. (2020). Efektifitas Kebijakan OJK Terkait Buyback Saham Terhadap Perubahan IHSG Di Masa Pandemi Covid-19. AGHNIYA: Jurnal Ekonomi Islam, 2(2).

[8] Dakwah, M. G. M. D. B., Alauddin, K. P. P. U., Jasad, H. U., \& Mahmuddin, H. STRATEGI DAKWAH STRUKTURAL MELALUI KEBIJAKAN PUBLIK.

[9] Jumrad, O. T., \& Sari, I. D. M. (2019). FUNGSI KOMUNIKASI DALAM ORGANISASI MELALUI GROUP CHAT WHATSAPP ORIFLAME. Jurnal Common, 3(1), 104-114.

[10] Arnus, S. H. (2018). Pengaplikasian Pola Computer Mediated Communication (CMC) dalam Dakwah. Jurnal Dakwah, 19(2), 191-203.

[11] Nasution, N. H. (2020). MANAJEMEN MASJID PADA MASA PANDEMI COVID 19. Yonetim: Jurnal Manajemen Dakwah, 3(01), 84-104.

[12] Hajar S, I. (2014). Sistem Pengelolaan Bimbingan Manasik Haji-Umrah pada PT. Al-Bayan Permata Ujas (Doctoral dissertation, Universitas Islam Negeri Alauddin Makassar).

[13] Cahyono, A. S. (2016). Pengaruh media sosial terhadap perubahan sosial masyarakat di Indonesia. Jurnal Publiciana, 9(1), 140-157.

[14] Ahmad, H., \& Amin, E. (2015). Integrasi Ayat-ayat Al-Quran dalam Seloko Adat Jambi: Transformasi Dakwah Kultural. Kontekstualita: Jurnal Penelitian Sosial Keagamaan, 30(1), 144813.

[15] Rozikan, M. (2017). Transformasi Dakwah Melalui Konseling Islami. INJECT (Interdisciplinary Journal of Communication), 2(1), 77-98.

[16] Uswatusolihah, U. (2015). Kesadaran dan Transformasi Diri Dalam Kajian Dakwah Islam dan Komunikasi. KOMUNIKA: Jurnal Dakwah dan Komunikasi, 9(2), 257-275. 